\title{
色彩还原-高显色指数有机单晶白光发光二极管器件
}

\author{
丁然 ${ }^{1}$, 冯晶 ${ }^{1 *}$, 孙洪波 ${ }^{2 *}$
}

1. 吉林大学电子科学与工程学院, 集成光电子学国家重点实验室, 长春 130012;

2. 清华大学精密仪器系, 精密测试技术及仪器国家重点实验室, 北京 100084

* 联系人, E-mail: jingfeng@jlu.edu.cn; hbsun@tsinghua.edu.cn

\section{Color reduction-high-color-rendering white organic single crystal-based light-emitting devices}

\author{
Ran Ding ${ }^{1}$, Jing Feng ${ }^{1 *} \&$ Hong-Bo Sun ${ }^{2 *}$ \\ ${ }^{1}$ State Key Laboratory of Integrated Optoelectronics, College of Electronic Science and Engineering, Jilin University, Changchun 130012, China; \\ ${ }^{2}$ State Key Lab of Precision Measurement Technology and Instruments, Department of Precision Instrument, Tsinghua University, Beijing 100084, China \\ * Corresponding authors, E-mail: jingfeng@jlu.edu.cn; hbsun@tsinghua.edu.cn \\ doi: 10.1360/TB-2020-0641
}

宋·苏轼《题西林壁》诗: “横看成岭侧成峰, 远近高低 各不同. 不识庐山真面目, 只缘身在此山中.” 光线对于视 觉观察至关重要, 如何才能更真切地辨识事物的精美细节 及璀璨色彩呢? 对于照明设备而言, 需要高显色指数的光 源才能更纯正地还原事物的色彩, 令其更饱和、更透彻. 白光有机发光二极管(white organic light-emitting diodes, WOLED) 具有高亮度、低功耗、响应速度快、超薄质轻及 可柔性化等优点, 在显示和照明领域具有广阔的应用前景, 近些年成为科研和工业界的研究热点 ${ }^{[1]}$. 对于 WOLED 器 件应用, 高显色指数 (CRI) 作为一项重要的指标受到人们 广泛的关注. 它是一种用于描述光源呈现真实物体颜色能 力的量值, 光源的 CRI 越高, 其颜色表现能力就越接近理 想的自然光. 随着研究的深人, 红绿蓝三色共混方案被认 为是实现 WOLED 高 CRI 的重要手段之一.

目前, 在 WOLED 中的有源层材料多以非晶和多晶有 机半导体材料为主, 由于这两类材料中存在大量杂质和缺 陷, 不可避免地会导致材料具有较低的载流子迁移率, 进 而严重影响器件的光电性能. 近年来, 由共轭分子构成的 有机单晶半导体材料, 因其晶体内具有规则分子排布、较 低的杂质含量和较高的载流子迁移率, 在有机光电子器件 领域展现出了巨大的应用潜力 ${ }^{[2]}$. 吉林大学冯晶教授和清 华大学孙洪波教授 ${ }^{[3,4]}$ 开展合作研究, 利用双分子掺杂手 段成功合成了白光有机单晶材料, 同时基于前期器件制备 和结构优化上的经验, 制备了具有高效率高显色指数的有 机单晶 WOLED 器件, 相关成果发表于 Advanced Functional Materials (图 1).
在有机电致发光器件领域, 染料分子掺杂技术被广泛 用于改变器件的发光颜色, 基于偶极与偶极间 Förster 或者 电子间 Dexter 能量传递机制，通过激子在客体分子上直接 复合或者能量从主体分子向客体分子传递的方式, 实现颜 色改变. 并通过减小材料聚集提高苂光内量子效率，可有 效提高发光器件的外量子效率. 研究团队考虑基于此技术 按照一定比例对晶体进行掺杂, 依靠能量传递的方式从主 体材料到客体材料, 苂光峰的位置发生移动, 从而改变晶 体的颜色.

选用 BSB-Me 蓝光晶体材料作为主体材料, 并四苯绿 光染料和并五苯红光染料分别作为客体材料，由于两种染 料分子材料的吸收峰与主体材料的苂光峰位置有交叉重 叠, 将更益于能量传递. 主客体材料按高掺杂比例共混研 磨后, 利用物理气相输运方法, 将并四苯和并五苯分子材 料分别掺人宽带隙 BSB-Me 主体材料中, 客体分子能级较 窄, 在晶体内形成势井, 对载流子具有束缚作用, 获得最 优的主体/客体匹配方案, 可提高复合发光效率, 以提高器 件的性能. 同时, 控制能量传递比例, 将能量完全转移给 客体材料, 制备颜色纯净的蓝色、绿色、红色的有机单晶 材料.

为了实现白光有机单晶材料, 研究团队考虑采用双掺 杂的方式, 通过在蓝光有机单晶主体材料中同时掺杂绿光 和红光染料分子, 精确控制掺杂比例, 当主体荧光峰强度 与客体苂光峰强度相当时, 红绿蓝三个互补色将会复合成 白光荧光. 利用时间相关单光子计数手段, 研究主体到客 体分子材料间属于部分能量转移过程, 实现均匀发光并覆 
(a)

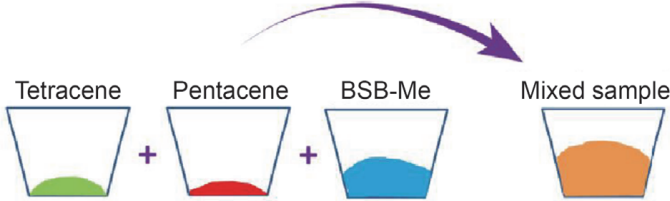

$\operatorname{Ar}$

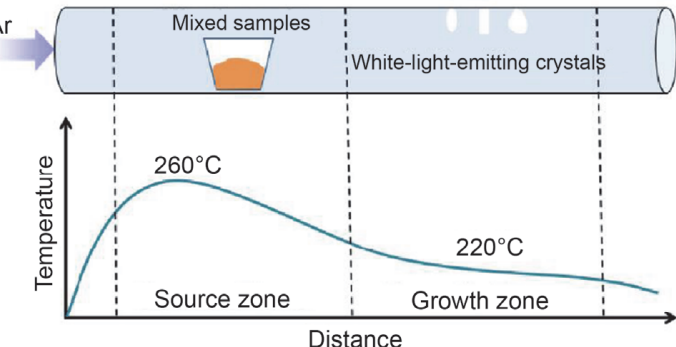

(d)

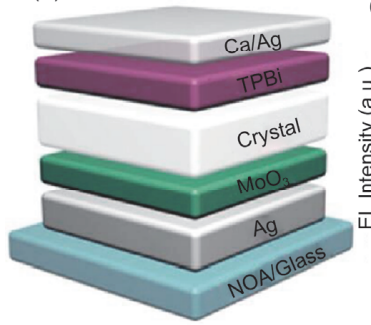

(e)

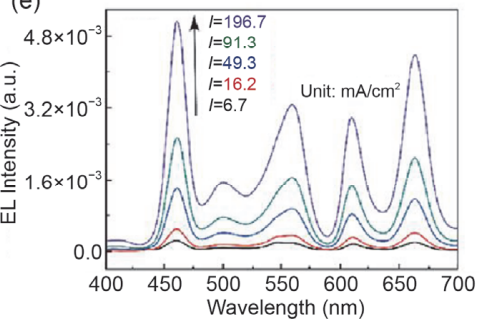

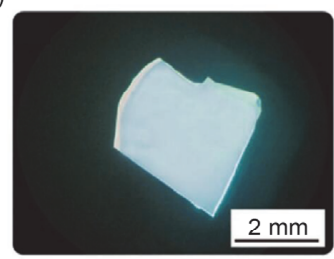

(c)

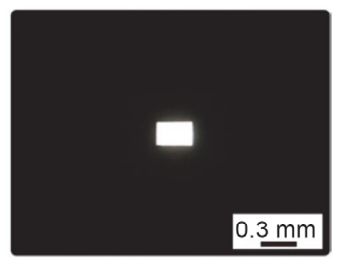

(f)

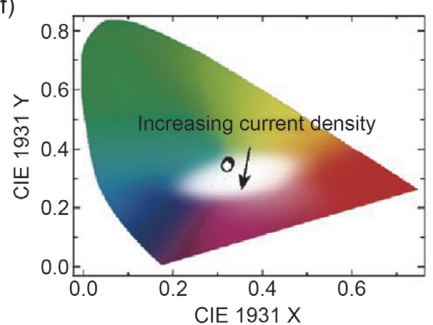

图 1 (网络版彩色)有机单晶 WOLED 发光器件及性能 ${ }^{[4]}$. (a) 物理气相输运方法制备双掺杂有机单晶材料; (b) 白光有机单晶材料菼光 照片; 有机单晶 WOLED 发光照片(c)及器件结构 (d); 白光电致发光光谱图(e)及 CIE 坐标图(f)

Figure 1 (Color online) Characteristics of crystal-based WOLEDs ${ }^{[4]}$. (a) Schematics of the growth of double-doped crystals by the physical vapor transport method. (b) Optical photograph of the double-doped crystal under the UV light. (c) Photographs of the operating crystal-based WOLEDs, and (d) device structure. (e) EL spectra and (f) CIE coordinates of the operating crystal-based WOLEDs varied with the increasing of the current density

盖红绿蓝波段的宽光谱的白光有机单晶材料.

利用这种双掺杂的白光有机单晶材料作为有源层, 结 合前期在器件制备方法和器件结构优化上的经验, 为促进 载流子的传输和注人, 采用过渡金属氧化物 $\mathrm{MoO}_{3}$ 作为阳 极修饰层, TPBi 作为电子传输层及空穴阻挡层, 成功制备 了具有高效率和高显色指数的有机单晶 WOLED 器件. 随 着驱动电流的增加, CRI 指数在 80 89 之间变化, 充分满足 照明应用的高显色指数需求. 其最大亮度和电流效率分别 达到 $793 \mathrm{~cd} / \mathrm{m}^{2}$ 和 $0.89 \mathrm{~cd} / \mathrm{A}$, 这是迄今报道的最优的有机
单晶 WOLED 发光性能.

合理选择主客体材料是实现晶体掺杂的重要条件, 首 先，选用适合气相升华的小分子材料，在升华过程中性质稳 定. 其次，保证选用的主客体材料的升华温度和结晶温度必 须相同或相近. 最后, 客体材料的吸收峰必须与主体材料的 菼光峰位置具有重叠和交叉，在掺杂晶体内部客实现完全 或部分能量转移. 该研究着眼于拓展晶体材料在光电器件 领域的应用, 探索提高有机晶体发光二极管器件性能的关 键技术, 为缩小与传统电致发光器件的差距作出贡献.

\section{推荐阅读文献}

1 Fan C, Yang C. Yellow/orange emissive heavy-metal complexes as phosphors in monochromatic and white organic light-emitting devices. Chem Soc Rev, 2014, 43: 6439-6469

2 Ding R, An M H, Feng J, et al. Organic single-crystalline semiconductors for light-emitting applications: Recent advances and developments. Laser Photon Rev, 2019, 13: 1900009

3 Ding R, Feng J, Dong F X, et al. Highly efficient three primary color organic single-crystal light-emitting devices with balanced carrier injection and transport. Adv Funct Mater, 2017, 27: 1604659

4 Ding R, Dong F X, An M H, et al. High-color-rendering and high-efficiency white organic light-emitting devices based on double-doped organic single crystals. Adv Funct Mater, 2019, 29: 1807606 